\title{
Antioxidant and Cytotoxic Activity of Beauveria bassiana Crude Mycelia Extracts against A-549 Cell Line
}

\author{
K. ASHOK PHANI KIRAN AND CH. MURALI MOHAN ${ }^{1 *}$ \\ Department of Biotechnology, GITAM Institute of Science, ${ }^{1}$ Department of Biotechnology, GITAM Institute of Technology, \\ GITAM (Deemed University), Visakhapatnam-530 045, India
}

\section{Kiran et al.: Antioxidant and Cytotoxic Activities of Beauveria bassiana Extracts}

Entomopathogenic fungus Beauveria bassiana widely used as biopesticide that specifically infect and kill insect pests. The present study was aimed to evaluate antioxidant and cytotoxic potentials of mycelia extracts of ten Beauveria bassiana isolates. Mycelia of Beauveria bassiana were extracted with hexane, ethyl acetate, methanol and water. Antioxidant activity possessed by the mycelial extracts was studied using the 1,1-diphenyl-2-picrylhydrazyl radical assay. Cytotoxic activity of mycelia extracts was tested using A-549 cell lines employing sulforhodamine B assay. Among all the mycelial extracts of Beauveria bassiana isolates, ethyl acetate extract exhibited highest antioxidant activity with an $\mathrm{IC}_{50}$ of $202.45 \mu \mathrm{g} / \mathrm{ml}$. Highest cytotoxic activity was observed with the ethyl acetate extract (116\%) while standard cisplatin showed $102 \%$. Further investigations needed on isolation and characterization of secondary metabolites that could be responsible for these activities in a bid to develop new compounds for cancers.

Key words: Cytotoxic activity, antioxidant activity, Beauveria bassiana extracts, lung carcinoma cell line (A-549) 
Natural products contain various compounds with antioxidants, antibacterial and cytotoxic properties ${ }^{[1]}$. Fungi are one of the groups of microorganisms, which are widely spread and having medicinal importance. Antioxidants are compounds that neutralize harmful free radicals and oxidants formed during metabolic reactions and help in prevention of cancer, cardiovascular diseases, neural disorders, Alzheimer's disease, Parkinson's disease, ulcerative colitis, alcohol-induced liver disease and other diseases ${ }^{[2]}$. Many antioxidant compounds are derived from natural sources including plants, fungi and bacteria $^{[3]}$. Fungal metabolites are known for having antibacterial, antifungal, larvicidal, antioxidant and other activities ${ }^{[4-6]}$. Beauveria bassiana is one of the most used entomopathogenic fungi as an alternative to chemical pesticides in insect pest management ${ }^{[7]}$. $B$. bassiana has been used by Korean traditional healers to treat many diseases by consuming infected and dead insects ${ }^{[8]}$. B. bassiana produces exogenous metabolites like iso-isariin, felinones, destruxins, beauvericin are having antiviral, anticancer, antiinflammatory and antimalarial properties ${ }^{[9]}$. Insecticidal toxins produced by $B$. bassiana during process of infection in hemolymph of insects induces cytotoxicity ${ }^{[10]}$. Cytotoxic activity is one of the most focused areas for medicinal activities of secondary metabolites produced by bacteria, fungi, plants and animals. Acquiring resistance to chemotherapeutic drugs made focus on new metabolites to act against cancer cells ${ }^{[11]}$. Cytotoxic compounds are most promising compounds for curing cancers or tumours in a most systemic way. Isolation and characterization of metabolites with cytotoxic activities has demand for curing various diseases $^{[12]}$. There have been very few reports on mycelial metabolites from $B$. bassiana with medicinal properties. The present investigation was taken up to study the antioxidant and cytotoxic properties of mycelial extract of ten $B$. bassiana isolates.

Ten $B$. bassiana isolates were used in the present study in which two isolates of $B$. bassiana (B. bassiana 1 and $B$. bassiana 2) were isolated from a local field infected insect Helicoverpa armigera on pigeon pea crop at Araku area of Visakhapatnam district and the remaining eight isolates (ARSEF 1166, ARSEF 3286, ARSEF 1512, ARSEF 1314, ARSEF 1149, ARSEF 1788, ARSEF 3120, ARSEF 326) were obtained from International Culture Collection Center
USDA-Agricultural Research Service Collection of Entomopathogenic Fungi (ARSEF). B. bassiana isolates were cultured on modified Sabouraud's dextrose broth fortified with $1 \%$ yeast extract and incubated using shaking incubator at $100 \mathrm{rpm}$ at $25^{\circ}$ temperature for $10 \mathrm{~d}$. After incubation, mycelia were separated using two fold muslin cloths under aseptic conditions and rinsed with sterilized double-distilled water. Mycelia were dried in hot air oven at $45^{\circ}$ for $48 \mathrm{~h}$ and packed in sterile polypropylene bags in aseptic conditions $^{[13]}$.

Dried mycelia was homogenized using motor and pestle under sterile conditions and $10 \mathrm{~g}$ of mycelia powder was extracted with $100 \mathrm{ml}$ of solvents hexane, ethyl acetate, methanol and water (AR grade, purchased from S. D. Fine-Chem Limited) for $24 \mathrm{~h}$ using Soxhlet extraction apparatus (Borosil). The crude extracts were concentrated at $40^{\circ}$ using rotary evaporator apparatus (Buchi r-300) and preserved in deep freezer (Blue Star Ltd.) at $-20^{\circ}$ until further use ${ }^{[14]}$.

Radical scavenging activity for the $B$. bassiana mycelia extracts was studied using 2,2diphenyl1-picrylhydrazyl (DPPH) purchased from SigmaAldrich. DPPH solution was prepared in methanol $(4 \mathrm{mg} / 100 \mathrm{ml})$ and placed in the dark for overnight for release of free radicals. Three millilitres of DPPH solution was mixed with mycelial extracts of concentrations 10, 25, 50, 100, 250, 500, 750 and $1000 \mu \mathrm{g} / \mathrm{ml}$ and incubated for $20 \mathrm{~min}$ at $37^{\circ}$ in a water bath and the decrease in absorbance was recorded at $515 \mathrm{~nm}$ was measured using spectrophotometer (Elico) against blank containing methanol in DPPH solution. The experiment was repeated for three times. Radical scavenging activity was calculated using the following Eqn. ${ }^{[15]}$, percent inhibition $=\left[\left(\mathrm{A}_{\mathrm{B}}-\mathrm{A}_{\mathrm{E}}\right) / \mathrm{A}_{\mathrm{B}}\right] \times 100$, where, $A_{B}$ is the absorbance of blank sample and $A_{E}$ is the absorbance of extract. Scavenging activity against the concentration of mycelia extracts was plotted and $\mathrm{IC}_{50}$ was determined.

Human lung carcinoma cell line (A-549) was obtained from NCIM, Pune and maintained on RPMI-1640

\footnotetext{
This is an open access article distributed under the terms of the Creative Commons Attribution-NonCommercial-ShareAlike 3.0 License, which allows others to remix, tweak, and build upon the work non-commercially, as long as the author is credited and the new creations are licensed under the identical terms
}

Accepted 06 June 2018

Revised 08 November 2017

Received 25 April 2017

*Address for correspondence

E-mail: murali.challa@gitam.edu

July-August 2018

Indian Journal of Pharmaceutical Sciences 
medium supplemented with $10 \%$ fetal bovine serum amended with $10 \mathrm{U}$ penicillin, $100 \mathrm{U}$ streptomycin and incubated at $37^{\circ}, 5 \% \mathrm{CO}_{2}$ was provided using $\mathrm{CO}_{2}$ incubator (Thermo Scientific) ${ }^{[16]}$. The cytotoxicity of the extracts was determined by testing on A-549 cell line. Colorimetric assay using sulforhodamine B (SRB) reaction was used for a quantitative measurement of cell growth and viability ${ }^{[17]}$. Cells $(190 \mu 1,5 \times 103$ cells per well) were added in 96-well microtiter plates and were grown in a drug free medium for $18 \mathrm{~h}$. Mycelium extracts $(1 \mu \mathrm{g} / \mu \mathrm{l})$ were added in aliquots of $10 \mu \mathrm{l}$ (dissolved in $\mathrm{DMSO} / \mathrm{H}_{2} \mathrm{O}, 1: 9$ ) and incubated for $48 \mathrm{~h}$ in $\mathrm{CO}_{2}$ incubator under $5 \% \mathrm{CO}_{2}$ and the cytotoxicity was measured by SRB methodology: cells were fixed by adding $50 \mu \mathrm{l}$ of cold $50 \%$ (w/v) trichloroacetic acid and incubated for $60 \mathrm{~min}$ at $4^{\circ}$. Plates were washed with deionized water and dried, $100 \mu$ of SRB solution $(0.4 \% \mathrm{w} / \mathrm{v} \mathrm{SRB}$ in $1 \%$ acetic acid) was added to each microtiter well and incubated for $10 \mathrm{~min}$ at room temperature. Unbound SRB was removed by washing with $1 \%$ acetic acid and plates were air dried. Add $100 \mu 1$ of Tris buffer to dissolve bound strain. Optical densities were read on an automated spectrophotometric plate reader (Biorad) at a single wavelength of $560 \mathrm{~nm}$. The activity of the mycelia extracts was given in percent growth inhibition (GI) for concentration tested $(0.050 \mu \mathrm{g} / \mu \mathrm{l})^{[18]}$. The experiment was repeated three times.
GI was calculated by using formula, $\%$ GI $=100-$ cell growth and percent cell growth-based was calculated on OD obtained at $560 \mathrm{~nm}$ with compare to the untreated cells. Negative \% GI- no GI (not active); $<50 \%$ GIweak GI (not active); 50 to $100 \%$ GI- moderate to high GI (active, GI effect); $100 \%$ GI- total GI (active, cytostatic effect); >100 \% GI- cell killing (active, cytotoxic effect).

Among the 10 isolates of $B$. bassiana mycelial extracts in water, methanol, ethyl acetate and hexane tested for antioxidant activity, ethyl acetate extracts of B. bassiana exhibited highest antioxidant activity (\% inhibition) of free radicals at $1000 \mu \mathrm{g} / \mathrm{ml}$ (fig. 1) and $\mathrm{IC}_{50}$ values (fig. 2). The order of antioxidant activity exhibited by the ethyl acetate extracts of ten $B$. bassiana isolates was $B$. bassiana 2 (95.59\%) followed by B. bassiana $1(94 \%)>$ ARSEF $1788(79.41 \%)>$ ARSEF $326 \quad(72.86 \%)>$ ARSEF $3120 \quad(69.57 \quad \%)>$ ARSEF $1149(66.18 \%)>$ ARSEF $1314(64.86 \%)>$ ARSEF $1512(62.32 \%)>$ ARSEF $3286(60.87 \%)>$ ARSEF 1166 (54.93 \%), fig.1. Abourashed ${ }^{[19]}$ reported that the 8-hydroxysilybin $(194.67 \mu \mathrm{g} / \mathrm{ml}), 7-\mathrm{O}-\mathrm{b}-\mathrm{D}-4-\mathrm{O}-$ methylglucopyranoside $(0.4667 \mu \mathrm{g} / \mathrm{ml})$, herbacetin 8-O-b-D-glucopyranoside $(1.7 \mu \mathrm{g} / \mathrm{ml}$; metabolites produced from $B$. bassiana) displayed antioxidant activity with good percent inhibition of free radicals. Study on 42 entomopathogenic fungi includes isolates of Beauveria, Metarhizium and Paecilomyces were

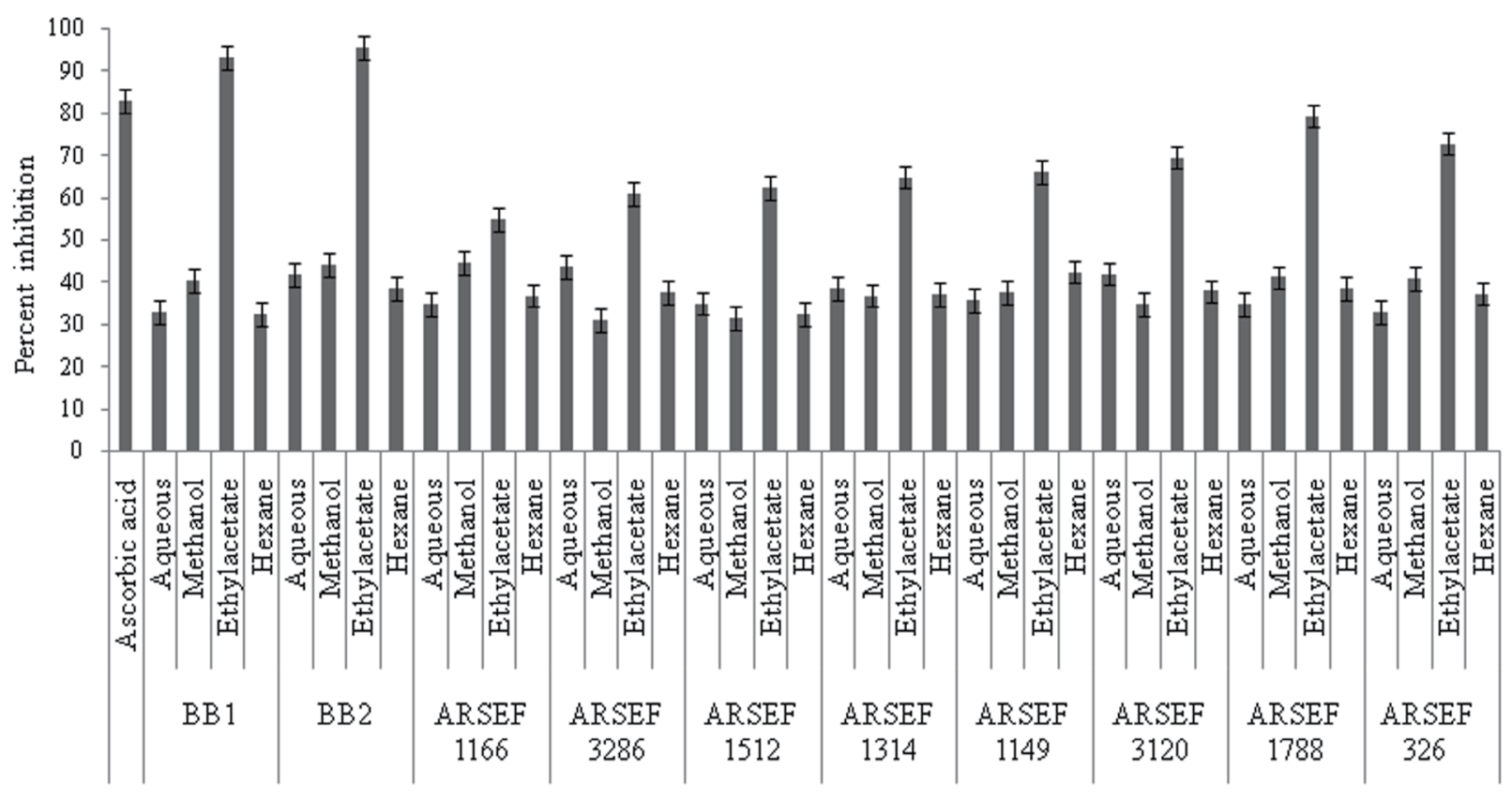

Beauveria bassiana mycelia extracts

Fig. 1: Inhibition of DPPH radical by extracts of $10 \mathrm{~B}$. bassiana isolates

Percent inhibition of DPPH radicals by water, methanol, ethyl acetate and hexane extracts of $10 \mathrm{~B}$. bassiana isolates. The results are mean $\pm \mathrm{SE}$ of three replicates 
having significant antioxidant activities with highest activity reported from $B$. bassiana ${ }^{[20]}$. Polysaccharides produced by the medicinal entomopathogenic fungi Cordyceps militaris have significant antioxidant and antitumor activities $^{[21]}$. Antioxidant enzymes were very important in overcoming insect ROS produced during infection and genetic analysis exposed many genes related to the enzymes and metabolites with antioxidant activity $^{[22]}$.

Among the extracts of ten $B$. bassiana isolates, ethyl acetate extract of $B$. bassiana showed highest cytotoxic activity of $116.16 \%$ GI, more than $100 \%$ GI activity on A-549 lung carcinoma cell lines followed by
B. bassiana $1(95 \%)>$ ARSEF $1788(88.45 \%)>$ ARSEF $1166(85.71 \%)>$ ARSEF $1512(81.39 \%)>$ ARSEF $1314(80.31 \%)>$ ARSEF $326(75.57 \%)>$ ARSEF 3286 (73.34 \%)>ARSEF 3120 (71.59\%) and low in ARSEF $1149(67.27 \%)$ showed cytotoxic activity in range of $50-100 \%$. B. bassiana mycelium water, methanol and hexane extracts showed GI activity below $50 \%$ indicating low or no activity (fig. 3). Cytotoxic activity was observed by ethyl acetate extracts of Cordyceps sinensis with $\mathrm{ED}_{50}$ less than $25 \mu \mathrm{g} / \mathrm{ml}$ and induced apoptosis through DNA fragmentation, chromatin condensation and proteolysis of ribose polymerase ${ }^{[23]}$. Cytotoxic activity by Hirsutella sp. entomopathogenic

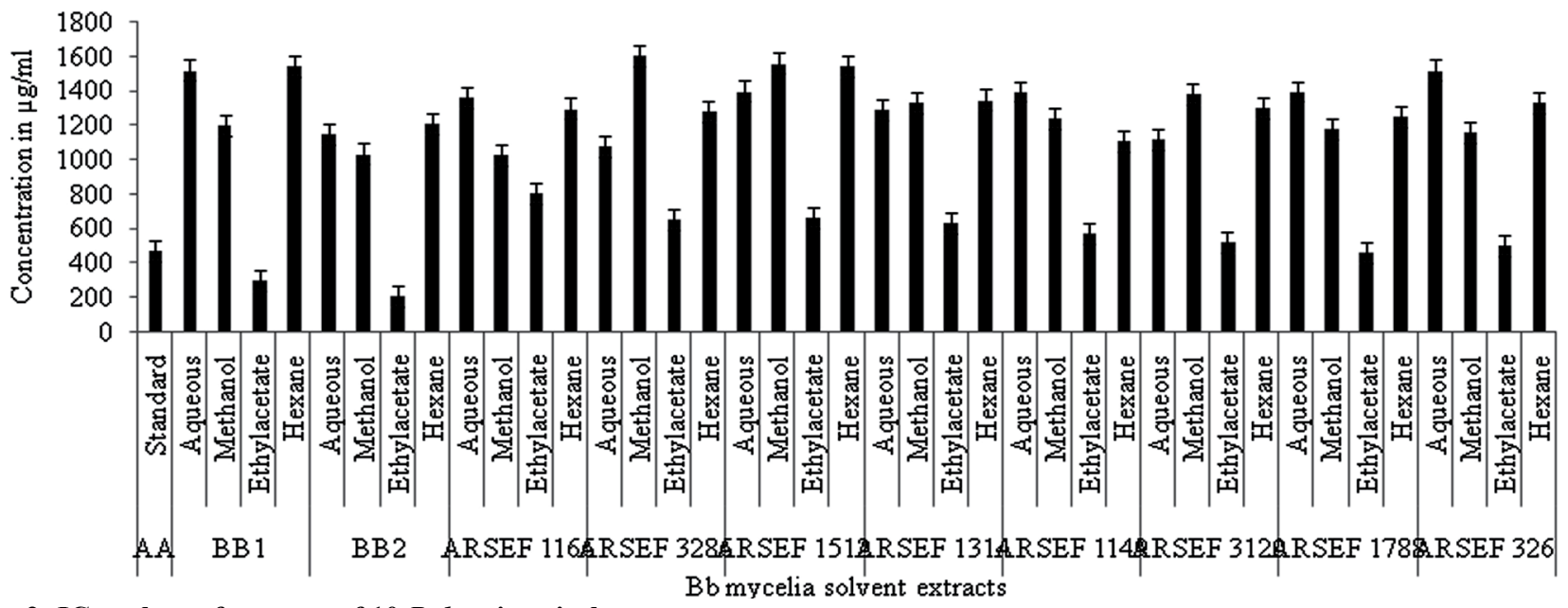

Fig. 2: $\mathrm{IC}_{50}$ values of extracts of $10 \mathrm{~B}$. bassiana isolates

$\mathrm{IC}_{50}$ values of water, methanol, ethyl acetate and hexane extracts of $10 \mathrm{~B}$. bassiana isolates. The results are mean $\pm \mathrm{SE}$ of three replicates

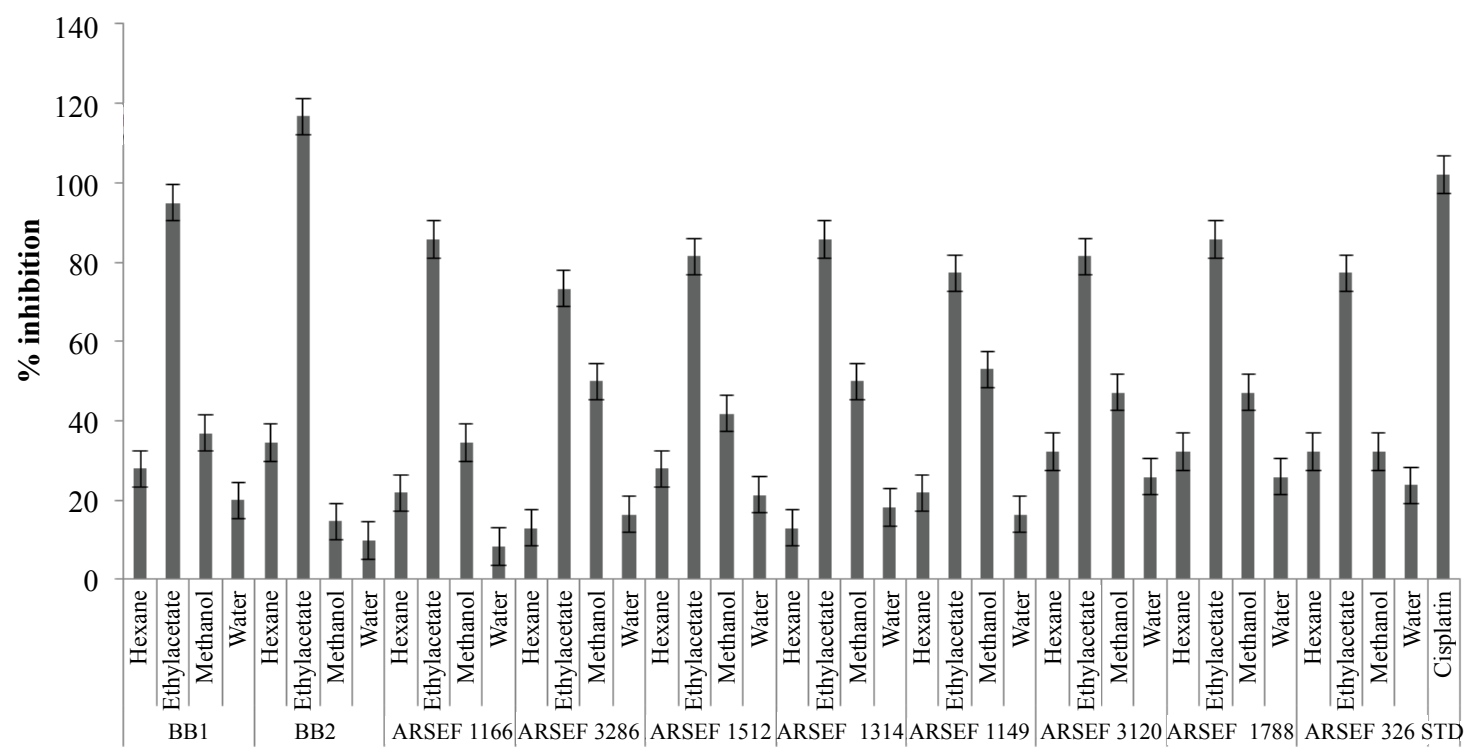

Beauveria bassiana extract in different sovent

Fig. 3: Cytotoxic activity of extracts of $10 \mathrm{~B}$. bassiana isolates on A-549 Cell lines

Cytotoxic activity of water, methanol, ethyl acetate and hexane extracts of 10 B. bassiana isolates on lung carcinoma (A-549). The results are mean $\pm \mathrm{SE}$ of three replicates 
fungi by using Chinese hamster ovary cells reported highest activity with $98 \%$ in ethyl acetate and methyl chloride extracts at $100 \mu \mathrm{g} / \mathrm{ml}$ concentration. Potential cytotoxic activity of Beauveria feline was tested against HL-60 (leukaemia), B16 (melanoma) and HCT8 (colon) cancer cell lines with significant cytotoxic activity. Antioxidant and cytotoxic activity exhibited by mycelia extracts of tested $B$. bassiana strains extracted with ethyl acetate as solvent can help in discovery of metabolites that are medicinally useful. Further work need to be carried out to isolate potential compound from $B$. bassiana mycelia extract. Present study infers that there are active and potential antioxidants and cytotoxic activity compounds in entomopathogenic fungus Beauveria sp. and further research can develop a potential drug for antioxidant and cytotoxicity.

\section{Acknowledgements:}

The authors thank Dr. Richard Humber, Insect Mycologist and Curator, ARSEF Collection of Entomopathogenic Fungal Cultures, Ithaca, USA for providing cultures. The authors also thank the help provided by the Management of GITAM (Deemed to be University) and Department of Biotechnology, GIT, GITAM University for allowing the use of their facilities to carry out the work.

\section{Conflict of interest}

The authors declare no conflicts of interest.

\section{REFERENCES}

1. Kuete V, Alibert-Franco S, Eyong KO, Ngameni B, Folefoc GN, Nguemeving JR, et al. Antibacterial activity of some natural products against bacteria expressing a multidrug-resistant phenotype. Int $\mathrm{J}$ Antimicrob Agents 2011;37(2):156-61.

2. Alam MN, Bristi NJ, Rafiquzzaman M. Review on in vivo and in vitro methods evaluation of antioxidant activity. Saudi Pharm J 2013;21(2):143-52.

3. Maestri BM, Nepote V, Lamarque AL, Zygadlo JA. Natural products as antioxidants. In: Imperato F, editor. Phytochemistry: advances in research. Trivandrum, India: Research Signpost 2006. p. 105-35.

4. Dias DA, Urban S, Roessner U. A Historical Overview of Natural Products in Drug Discovery. Metabolites 2012;2:303-36.

5. Demain AL. Pharmaceutically active secondary metabolites of microorganisms. Appl Microbiol Biotechnol 1999;52(4):455-63.

6. Keller C, Maillard M, Keller J, Hostettmann K. Screening of European fungi for antibacterial, antifungal, larvicidal, molluscicidal, antioxidant and free-radical scavenging activities and subsequent isolation of bioactive compounds. Pharm Biol 2002;40(7):518-25.

7. Chandler D, Bailey AS, Tatchell GM, Davidson G, Greaves
J, Grant WP. The development, regulation and use of biopesticides for integrated pest management. Philos Trans R Soc Lond B Biol Sci 2011;366(1573):1987-98.

8. Pemberton RW. Insects and other arthropods used as drugs in Korean traditional medicine. J Ethnopharmacol 1999;65(3):207-16.

9. Du FY, Li XM, Zhang P, Li CS, Wang BG. Cyclodepsipeptides and Other O-Containing Heterocyclic Metabolites from Beauveria felina EN-135, a Marine-Derived Entomopathogenic Fungus. Mar Drugs 2014;12(5):2816-26.

10. Sood S, Sandhu SS, Mukherjee TK. Pharmacological and Therapeutic Potential of Beauvericin: A Short Review. J Proteomics Bioinform 2017;10(1):18-23.

11. Alfarouk KO, Stock CM, Taylor S, Walsh M, Muddathir AK, Verduzco D, et al. Resistance to cancer chemotherapy: failure in drug response from ADME to P-gp. Cancer Cell Int 2015;15(71):1-13.

12. $\mathrm{Hu} \mathrm{Y,} \mathrm{Fu} \mathrm{L.} \mathrm{Targeting} \mathrm{cancer} \mathrm{stem} \mathrm{cells:} \mathrm{a} \mathrm{new} \mathrm{therapy} \mathrm{to} \mathrm{cure}$ cancer patients. Am J Cancer Res 2012;2(3):340-56.

13. Fang W, Leng B, Xiao Y, Jin K, Ma J, Fan Y, et al. Cloning of Beauveria bassiana chitinase gene bbchit1 and its application to improve fungal strain virulence. Appl Environ Microbiol 2005;71:363-70.

14. Dudonne S, Vitrac X, Coutière P, Woillez M, Mérillon JM. Comparative study of antioxidant properties and total phenolic content of 30 plant extracts of industrial interest using DPPH, ABTS, FRAP, SOD, and ORAC assays. J Agric Food Chem 2009;57(5):1768-74.

15. Shen J, Xie Y, Sun ML, Han R, Qin ZH, He JK. Antitumor activity of cobrotoxin in human lung adenocarcinoma A549 cells and following transplantation in nude mice. Oncol Lett 2014;8(5):1961-5.

16. Skehan PA, Storeng R, Monks A, Mcmahon J, Vistica $\mathrm{D}$, Warren JT, et al. New colorimetric cytotoxicity assay for anticancer drug screening. J Natl Cancer Inst 1990;82:1107-12.

17. Adebayo AH, Tan NH, Aakindahunsi AA, Zeng GZ, Zhang YM. Anticancer and antiradical scavenging activity of Ageratum conyzoides 1. (asteraceae). Pharmacogn Mag 2010;6:62-6.

18. Abourashed EA, Mikell JR, Khan IA. Bioconversion of silybin to phase I and II microbial metabolites with retained antioxidant activity. Bioorg Med Chem 2012;20(9):2784-8.

19. Zohri AA, Moharram AM, Ghani OAAE. Antioxidant potentialities of some strains belonging to endophytic, entomopathogenic and saprophytic fungi. Eur $\mathrm{J}$ Biol Res 2017;7(1):76-85.

20. Marques AMV, Lira SP, Berlinck RGS, Seleghim MHR, Sponchiado SRP, Tornisielo SMT, et al. A multi-screening approach for marine-derived fungal metabolites and the isolation of cyclodepsipeptides from Beauveria felina. Quim Nova 2008;31(5):1099-103.

21. Ortiz-Urquiza A, Keyhani NO. Stress response signaling and virulence: insights from entomopathogenic fungi. Curr Genet 2015;61(3):239-49.

22. Chen W, Liu G, Yang H, Wu Z, Yang H. Production and Preliminary Characterization of Antioxidant Polysaccharide by Submerged Culture of Culinary and Medicinal Fungi Cordyceps militaris CICC14013. Int J Food Eng 2016;13(1):20160126.

23. Zhang Q, Wu J, Hu Z, Li D. Induction of HL-60 apoptosis by ethyl acetate extract of Cordyceps sinensis fungal mycelium. Life Sci 2004;75 (24):2911-9. 